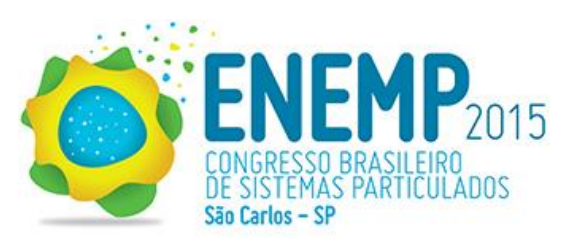

\title{
PRODUÇÃO DE MALTE DE NOZES DE MACADÂMIA E MODELAGEM MATEMÁTICA DA SUA SECAGEM POR CONVECÇÃO NATURAL
}

\author{
L.V. MARIM ${ }^{*}$, F. M. R. SILVA², D. J. M. SARTORI ${ }^{3}$ e L. ARRIECHE \\ 1* Bolsista PIBIC, Universidade Federal do Espírito Santo, Departamento de Engenharias e Tecnologia \\ ${ }^{2}$ Bolsista PIVIC, Universidade Federal do Espírito Santo, Departamento de Engenharias e Tecnologia \\ ${ }^{3}$ Professor, Universidade Federal de São Carlos, Departamento de Engenharia Química \\ ${ }^{4}$ Professor, Universidade Federal do Espírito Santo, Departamento de Engenharias e Tecnologia \\ *email: layravalani@gmail.com
}

\begin{abstract}
RESUMO
O produto da germinação interrompida de uma semente seguido de secagem é chamado de malte. Esta pesquisa contemplou a produção de malte de sementes de macadâmia verdes e maduras, via germinação em sacola plástica, algodão hidrófilo e areia autoclavada. A cada teste germinativo foi associado um método de quebra de dormência e maceração. As sementes germinaram por 30 dias e, em função das que brotaram, foi calculado o Índice Germinativo. O maior Índice obtido foi de $13,64 \%$, referentes a sementes maduras sem quebra de dormência e maceração, germinadas em areia autoclavada. As amêndoas foram extraídas da casca e congeladas a $-18^{\circ} \mathrm{C}$ para posterior etapa de secagem. A secagem é fundamental na produção e na conservação das qualidades nutricionais de produtos agrícolas. Assim, foi abordada a modelagem matemática da secagem, por convecção natural, de nozes de macadâmias maltadas. Por meio de balanços de massa e energia em coordenadas esféricas, foram desenvolvidos modelos para simular os perfis de temperatura e umidade. As equações que representaram os fenômenos de transferência de calor e de massa foram obtidas a partir do modelo de Fourier e de Fick e foram solucionadas com o auxílio do programa Matlab ${ }^{\circledR}$ e com a utilização dos métodos de diferenças finitas e de RungeKutta.
\end{abstract}

\section{INTRODUÇÃO}

No Brasil, a região sudeste é a principal produtora de macadâmia, sendo os estados de maior produção São Paulo e Espírito Santo (PENONI, 2011).

Com esta disponibilidade em evidência, procurou-se desenvolver o malte dessa noz a partir de um ambiente de crescimento asséptico, de modo que esse malte posteriormente possa ser empregado na indústria alimentícia.

O processo de obtenção do malte é denominado maltagem. A semente é submetida a um ambiente artificial de germinação e posterior secagem controlada.

A secagem é um dos processos mais importantes quando se trata de processamento de alimentos e estocagem de grãos. Esse processo consiste na transferência parcial de líquido (geralmente água) de um sólido. $\mathrm{O}$ processo de secagem pode ser explicado pela transferência de umidade para o ar de secagem causado por uma força motriz, normalmente por diferença de temperatura, pressão ou concentração (FORTES, 1978).

O objetivo principal da secagem é aumentar a vida útil dos alimentos. A redução do conteúdo de água diminui a atividade 
enzimática, reduzindo assim o crescimento de microrganismos e a progressão de reações químicas indesejáveis. Porém, dependendo da forma de como o processo é conduzido, a secagem de produtos alimentícios pode causar transformações em diferentes atributos de qualidade, como escurecimento, encolhimento e perda de nutrientes. As composições dos alimentos são facilmente alteradas em secagens que utilizam temperaturas altas, resultando em deterioração na qualidade do produto (XINGUO, J., PETER, J. e SHANE, 1990).

O processo de secagem também pode ser usado como pré-tratamento de alimentos. Algumas operações de separação como moagem ou mistura se tornam mais simples quando a umidade do material é reduzida. Do ponto de vista econômico, a secagem possui uma função muito importante. Como consequência da perda de água, alimentos secos são mais leves e menos volumosos quando comparados com os naturais, o que facilita $\mathrm{o}$ acondicionamento e transporte (DELGADO, J. M. P. Q. e BARBOSA, 2014).

Assim, este trabalho teve como objetivo o estudo da produção do malte de macadâmia e a modelagem matemática do seu processo de secagem.

\section{MATERIAIS E MÉTODOS}

\subsection{Preparação das amostras para a produção do malte}

Foram utilizadas sementes de macadâmia verdes e maduras in natura, referentes às colheitas dos anos de 2013/2014, cedidas pela Cooperativa Agroindustrial dos Produtores de Noz Macadâmia - COOPMAC localizada na cidade de São Mateus, Espírito Santo.

As sementes foram lavadas manualmente e imersas em solução de álcool etílico $70 \%$ por 10 minutos. Em seguida, o carpelo de todas as sementes foi retirado com o auxílio de uma faca, ficando a semente apenas com a casca e, no seu interior, a amêndoa. Os experimentos foram conduzidos no Laboratório de Eficiência Energética I do Prédio de Pós-Graduação em Energia - UFES (Campus Ceunes).

As sementes foram separadas em dois grandes grupos: sementes verdes (SV) e sementes maduras (SM). Cada grupo foi subdividido em dois pequenos grupos: sementes com quebra de dormência (CQD) e sem quebra de dormência (SQD). Cada processo de quebra de dormência foi respectivamente relacionado a um tempo de maceração e posterior germinação, conforme mostra a Tabela 1.

Tabela 1 - Relação entre quebra de dormência e germinação.

\begin{tabular}{lcr}
$\begin{array}{l}\text { Quebra de } \\
\text { Dormência }\end{array}$ & $\begin{array}{r}\text { Maceração } \\
\text { (horas) }\end{array}$ & $\begin{array}{r}\text { Germinação } \\
\text { (ambiente } \\
\text { de }\end{array}$ \\
\hline $\begin{array}{l}\text { Rachadura } \\
\text { na casca }\end{array}$ & 96 & $\begin{array}{r}\text { Sacola } \\
\text { plástica }\end{array}$ \\
$\begin{array}{l}\text { Imersão em } \\
\text { água em } \\
\text { transparente }\end{array}$ \\
$\begin{array}{l}100{ }^{\circ} \mathrm{C} \text { até } \\
\text { atingir } \\
\text { temperatura } \\
\text { ambiente }\end{array}$ \\
$\begin{array}{l}\text { Imersão em } \\
\text { água em } \\
\text { torno de } \\
100{ }^{\circ} \mathrm{C} \\
\text { durante } 10\end{array}$ \\
minutos
\end{tabular}

Fonte: Autores (2015)

\subsection{Metodologia}

\subsubsection{Germinação}

A quebra de dormência por rachadura na casca foi feita com o auxílio de um martelo 
e uma pinça metálica, de modo que se abriu na casca uma quase imperceptível fenda para entrada de água, e posterior desenvolvimento do processo germinativo.

O segundo método para a quebra de dormência consistiu na imersão total das sementes em água a aproximadamente $100{ }^{\circ} \mathrm{C}$ durante um período de 1 hora.

A quebra de dormência para o terceiro método foi a total imersão das sementes em água a aproximadamente $100{ }^{\circ} \mathrm{C}$ durante um período de 10 minutos.

A etapa de maceração consistiu na imersão de todas as sementes (SM e SV, CQD e SQD) em água a temperatura ambiente durante suas respectivas horas (Tabela 1). A cada 12 horas a água foi trocada.

Em seguida, as sementes foram postas para germinar sob as mesmas condições daquelas que não sofreram quebra de dormência. Primeiramente, 37 SM SQD e 37 SV SQD foram colocadas para germinar no interior de sacolas plásticas transparentes. A borda das sacolas permaneceu entreaberta de maneira a ocorrer circulação de ar ambiente e espaço suficiente para que fosse possível adicionar algumas gotas de água. As sacolas foram mantidas sempre umedecidas, expostas ao sol matinal. O tempo de germinação durou 30 dias.

Em segundo lugar, a germinação em algodão comportou $70 \mathrm{SM}$ das quais 45 são SQD além de $70 \mathrm{SV}$, das quais 45 são SQD. Dentro de dois vasilhames, todas as sementes foram envolvidas por camadas de aproximadamente $1,5 \mathrm{~cm}$ de algodão hidrófilo. $\mathrm{O}$ algodão e as sementes foram mantidos constantemente umedecidos e os vasilhames recebiam luminosidade solar matinal. Aos primeiros indícios de broto cessou-se a germinação. O tempo decorrido foi de 30 dias.

$\mathrm{O}$ último método consistiu na germinação em areia. Nenhuma das sementes destinadas a esse método passou pela etapa de maceração. A areia foi autoclavada por 30 minutos a aproximadamente $120{ }^{\circ} \mathrm{C}$ para garantia de esterilidade. Em seguida foi despejada em vasilhames e em camadas de aproximadamente $2 \mathrm{~cm}$, de modo a cobrir todas as sementes. A areia e as sementes foram mantidas constantemente umedecidas e os vasilhames foram cobertos por uma tela se sombreamento, a fim de se evitar a contaminação da areia por insetos e detritos. O recipiente ficou exposto à luz solar das $7 \mathrm{~h}$ às $11 \mathrm{~h}$ e das $16 \mathrm{~h}$ às $18 \mathrm{~h}$. Com o início dos brotos finalizou-se a germinação que teve duração de 30 dias.

Após a germinação, contou-se o número de sementes que brotaram e calculouse o Índice Germinativo (IG), segundo a equação 1:

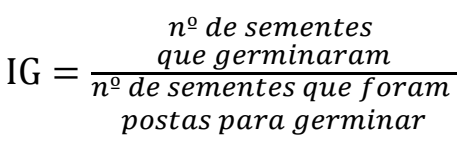

Posteriormente as amêndoas foram retiradas da casca e congeladas a aproximadamente $-18{ }^{\circ} \mathrm{C}$ para posterior secagem.

\subsubsection{Secagem}

Sementes verdes com quebra de dormência, sem rachadura e sem broto foram selecionadas e separadas em três conjuntos distintos para que fosse feita a triplicata dos experimentos. A massa de cada conjunto foi medida e cada um dos seus elementos fotografados. Em seguida, as amostras foram colocadas em uma estufa (modelo S250SD) a aproximadamente $61^{\circ} \mathrm{C}$, onde permaneceram em intervalos de 15 minutos. $\mathrm{O}$ procedimento foi repetido até que a variação da massa não fosse significativa na terceira casa decimal. Para a determinação da umidade de equilíbrio, as amostras permaneceram dentro da estufa a 105 graus Celsius por aproximadamente 12 horas.

Medidas de temperatura também foram feitas para as amostras. Um termopar tipo $\mathrm{K}$ foi utilizado para registrar a temperatura durante o processo de secagem. Um dos terminais foi 
inserido no centro da amostra e sua temperatura foi medida a cada 15 minutos.

Para o estudo da secagem de nozes de macadâmia, propuseram-se dois modelos matemáticos. No primeiro modelo, tanto a difusividade efetiva quanto a condutividade térmica são constantes e ocorrem transferências simultâneas de massa e de energia. No segundo modelo, a difusividade efetiva é dependente do conteúdo de umidade e varia com o tempo e com o espaço. Somente o modelo de transferência de massa é analisado. Também foram feitas considerações sobre a geometria das nozes e condições do processo. As considerações são apresentadas a seguir:

- Secagem por convecção natural;

- Modelagem matemática

em coordenadas esféricas;

- As transferências de massa e de calor ocorrem somente na direção radial;

- A transferência de massa é independente da transferência de calor

- Secagem de amostra única e

- Temperatura do ar de secagem constante.

\subsubsection{Modelo de transferência de massa e de} calor combinadas

Este modelo considera que as transferências de massa e calor ocorrem simultaneamente e que a transferência de massa é a etapa determinante do processo de secagem. Como uma primeira abordagem, considerou-se que tanto a difusividade efetiva quanto a condutividade térmica não variam com o tempo ou com a posição. Considera-se também que a água é transferida do interior do sólido até sua superfície por difusão e, em seguida, transferida ao ar de secagem por convecção. Com relação à transferência de energia, calor é transferido do ar de secagem para a superfície do sólido por convecção e da superfície para o interior por difusão. As equações que descrevem os fenômenos de transferência de massa e calor são representadas, respectivamente, pelas equações 2 e 3 .

$\frac{\partial \Psi}{\partial \tau}=\left(\frac{R_{S}}{R}\right)^{2} \frac{D_{e f}}{D_{e f f}}\left[\frac{\partial^{2} \Psi}{\partial \xi}+\frac{2}{\xi} \frac{\partial \Psi}{\partial \xi}\right]$

$\frac{\partial \Theta}{\partial \tau}=L_{e}\left(\frac{R_{S}}{R}\right)^{2}\left[\frac{\partial^{2} \Theta}{\partial \xi}+\frac{2}{\xi} \frac{\partial \Theta}{\partial \xi}\right]$

2.2.4 Condições inicial e de contorno para a transferência de massa

$\mathrm{Na}$ condição inicial assumiu-se que a umidade no sólido esférico é uniforme em todas as posições antes do início do processo de secagem. Uma condição de contorno considera que, na superfície do sólido, o fluxo difusivo de massa se iguala ao fluxo convectivo. Finalmente, uma condição de simetria assume que o fluxo de massa no centro da esfera é nulo, pois possui a mesma magnitude para qualquer valor das dimensões angulares. As condições inicial, de contorno e de simetria são dadas pelas equações 4,5 e 6 , respectivamente.

$\Psi=1 \operatorname{para} \tau=0, \forall \xi$

$\left.\frac{\partial \Psi}{\partial \xi}\right|_{\xi=1}=-\left.3 B i_{m} \Psi\right|_{\xi=1}, \tau \geq 0, \xi=1$

$\frac{\partial \Psi}{\partial \xi}=0 \operatorname{para} \tau \geq 0, \xi=0$

2.2.5 Condição inicial e de contorno para a transferência de calor

De forma análoga à transferência de massa, a condição inicial estabelece que a temperatura do sólido é uniforme em toda a sua extensão. A condição de simetria considera que o fluxo de calor no centro da esfera é nulo. A condição de contorno estabelece que, na superfície do sólido, o somatório do fluxo de calor e do termo que representa o calor de vaporização de água se iguala ao fluxo convectivo. As condições inicial, de contorno e de simetria são dadas pelas equações 7, 8 e 9, respectivamente. 
$\Theta=1 \operatorname{para} \tau=0, \forall \xi$

$\left.\frac{\partial \Theta}{\partial \xi}\right|_{\xi=1}=\frac{\bar{\lambda}}{L e_{0}} \frac{\partial \Psi}{\partial \xi}-\left.3 B i(\Theta-1)\right|_{\xi=1}, \tau \geq 0, \xi=1$

$\frac{\partial \Theta}{\partial \xi}=0$ para $\tau \geq 0, \xi=0$

2.2.6 Modelo de transferência de massa com difusividade variável

Neste modelo a difusividade varia com o tempo e com a posição. Por motivos de simplificação, considerou-se que a difusividade é uma função apenas da umidade do sólido. As difusividades podem ser representadas pelas equações 10 e 11 .

$D_{e f}=a+b X$

$D_{e f}=a X^{b}$

em que, $a$ e $b$ são parâmetros de ajuste. Substituindo as Equações 10 e 11 na equação da Segunda Lei de Fick, tem-se:

$\frac{\partial \Psi}{\partial \tau}=\frac{1}{9 R^{2}}\left\{[a+b X] \frac{\partial^{2} \Psi}{\partial \xi^{2}}+b\left(X_{0}-X_{e}\right)\left(\frac{\partial \Psi}{\partial \xi}\right)^{2}+\right.$

$\left.\frac{2}{\xi}[a+b X] \frac{\partial \Psi}{\partial \xi}\right\}$

para a difusividade efetiva variando linearmente com o conteúdo de umidade do sólido. Para o caso da difusividade variar potencialmente com a umidade, tem-se:

$\frac{\partial \Psi}{\partial \tau}=\frac{1}{9 R^{2}}\left\{a[X]^{b} \frac{\partial^{2} \Psi}{\partial \xi^{2}}+a b\left(X_{0}-X_{e}\right)[X]^{b-1}\left(\frac{\partial \Psi}{\partial \xi}\right)^{2}+\right.$

$\left.\frac{2}{\xi}\left\{a[X]^{b}\right\} \frac{\partial \Psi}{\partial \xi}\right\}$

No que diz respeito à metodologia numérica, foi utilizado o método das diferenças finitas para discretizar o sistema de equações do modelo, para cada ponto nodal em uma malha estruturada para cada caso, incluindo as condições de contorno e de simetria. $\mathrm{O}$ sistema de equações resultante foi integrado na dimensão temporal pelo método de Runge-Kutta e o programa Matlab® foi utilizado para solução numérica e simulação. Nos modelos de transferência de massa, a constante de secagem e os parâmetros a e b foram ajustados utilizando como critério o método dos quadrados mínimos.

\subsection{Determinação das propriedades da noz de macadâmia}

As propriedades da macadâmia como calor específico, difusividade térmica, massa específica e condutividade térmica foram determinadas de acordo com relações empíricas propostas por Choi e Okos (1986). A difusividade efetiva foi obtida a partir da constante de secagem.

\section{RESULTADOS E DISCUSSÕES}

\subsection{Produção do malte}

A quebra de dormência no primeiro experimento não foi satisfatória, visto que o martelo abriu fendas muito grandes na maioria das sementes. O tempo de maceração de 96 horas foi muito prolongado e provocou escurecimento da água e odor desagradável. Durante os 30 dias de germinação, as sementes desenvolveram fungos no interior das sacolas plásticas e precisaram ser descartadas. Nenhuma semente germinou, isto é, IG nulo.

No segundo experimento, observou-se que as sementes CQD exibiram IG menor do que aquelas que não sofreram quebra de dormência. A etapa de maceração não influenciou na germinação das sementes. Entre as SM postas para germinar, duas exibiram brotos. Assim, o IG foi calculado segundo a equação 1 foi de 2,86\%. Entre as SV, apenas uma exibiu broto, e o IG correspondente foi de $1,43 \%$. A partir do IG do segundo experimento chegou-se a conclusão de que as SM são melhores para germinar, por isso foram escolhidas somente SM para o terceiro experimento. As SM SQD apresentaram IG de 13,64\%. Já as SM CQD apresentaram IG nulo. $\mathrm{O}$ método de esterilização da areia em autoclave foi adequado, pois não houve 
desenvolvimento de fungos. A areia manteve seu aspecto inicial até o fim da germinação, sem alteração de sua cor e/ou odor.

Observou-se também que as sementes que exibiram broto foram aquelas que receberam maior luminosidade por estarem localizadas na parte mais superficial do vasilhame.

\subsection{Secagem}

A Figura 1 mostra a Densidade de fluxo de massa em função da umidade em base seca. É possível constatar que somente o período de taxa decrescente está presente na secagem da noz de macadâmia. Em materiais biológicos existe uma resistência à transferência de massa no interior do produto. A taxa de evaporação da superfície para o meio envolvente é superior à taxa de reposição de umidade do interior até à superfície.

Figura 1 - Densidade de fluxo de massa em função da umidade em base seca

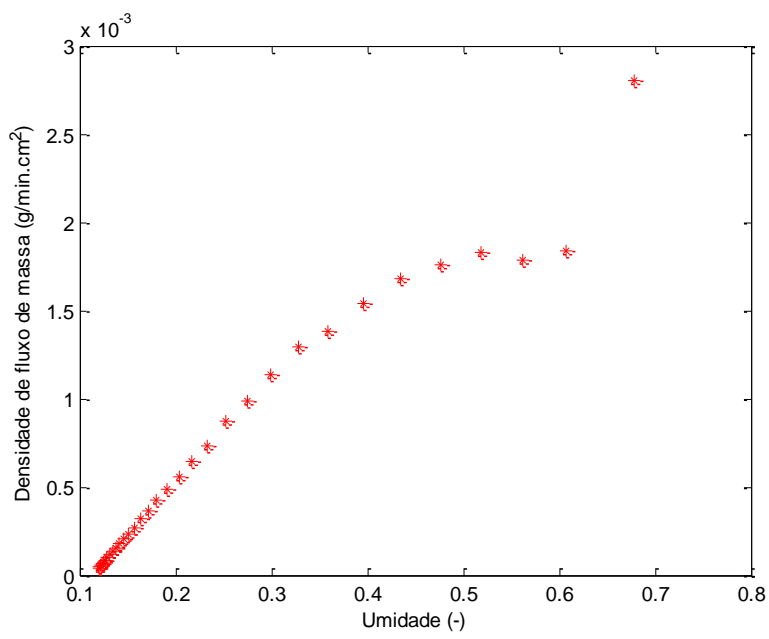

Como consequência, este período de taxa de secagem constante é inexistente neste tipo de material (MUJUMDAR, 2009; PARK, K. J. B.; PARK, K. J.; CORNEJO, F. E. P.; FABBRO, I. M. D., 2008; PARK, K. J.; ANTONIO, G.C.; OLIVEIRA, R. A.; PARK, K. J. B., 2007 e SHERWOOD, 1929a, 1929b).

\subsection{Modelo de difusividade mássica e condutividade térmica constantes}

A Figura 2 mostra a redução do conteúdo de umidade da amostra durante o processo de secagem. Os pontos em verde representam os resultados experimentais. A curva em azul representa a simulação numérica.

Figura 2 - Resultados da simulação com os resultados experimentais, de acordo com a Equação 2

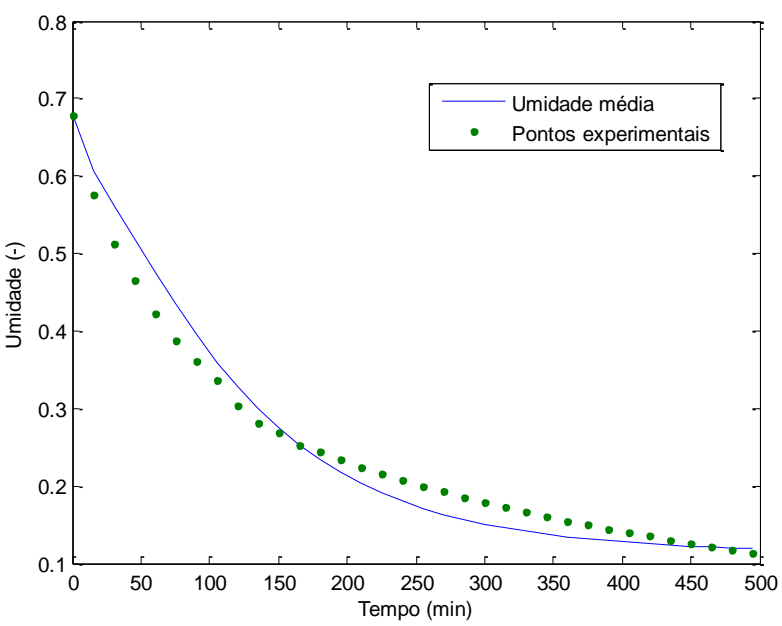

A umidade da amostra decresce rapidamente no início do processo de secagem. Em aproximadamente 200 minutos, a redução de umidade se torna mais lenta em relação ao início do processo. Isso pode ser explicado por meio da análise da Lei de Fick, em que a derivada que representa a força motriz para a transferência de massa se aproxima de zero. Isto significa que a taxa de fluxo de massa difusivo diminui e a taxa de transferência de massa se torna mais lenta. A umidade da amostra se estabiliza em 0,11 com aproximadamente $400 \mathrm{~min}$.

Uma discussão similar pode ser feita para a temperatura, representado pela Figura 3. Os pontos em azul representam os pontos resultados experimentais. A curva em vermelho representa a temperatura do centro da amostra. Nos primeiros 100 minutos a temperatura da amostra aumenta rapidamente. Gotículas de água se formam na superfície da amostra. Como o conteúdo de umidade da noz 
de macadâmia é relativamente baixo em relação a outros produtos alimentícios como as frutas, as áreas expostas (sem cobertura das gotículas de água) aquecem e a temperatura da amostra aumenta. Após 100 minutos, o aumento da temperatura progride de forma mais lenta. $\mathrm{O}$ termo que representa a força motriz na lei de Fourier tende a zero. Isto implica que o fluxo de energia decresce e a taxa de transferência de energia se torna muito lenta. A temperatura da noz tende assintoticamente à temperatura do ar de secagem. De acordo com a simulação, a temperatura atingida aos $500 \mathrm{~min}$ foi de $60,8^{\circ} \mathrm{C}$ enquanto a temperatura registrada pelo termopar foi de $60,4^{\circ} \mathrm{C}$.

Figura 3 - Resultados da simulação com os resultados experimentais, de acordo com a Equação 3

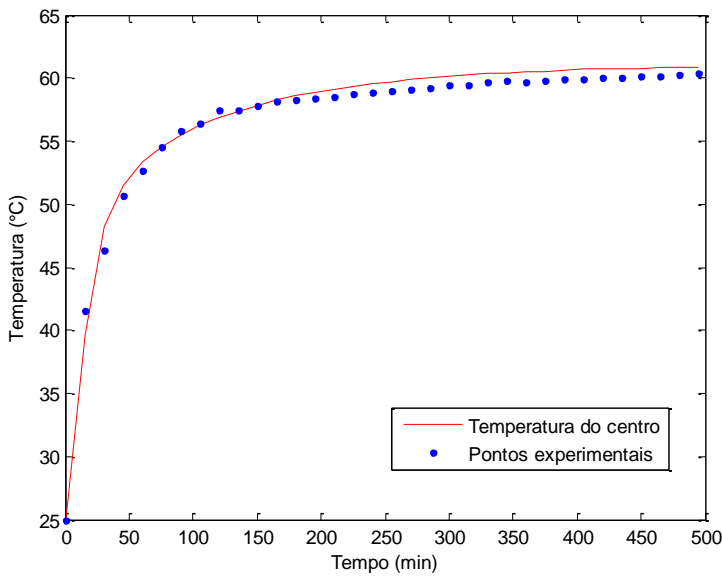

A dependência da temperatura em relação ao raio da amostra pode ser observada na Figura 4. Durante os primeiros minutos de secagem, é possível notar uma pequena diferença entre a temperatura da superfície e a do centro. Com a progressão da secagem, esta diferença se torna cada vez menor. Embora a amostra seja um material biológico e, portanto, é um mau condutor de calor, seu pequeno tamanho contribui para a condução de calor e a amostra aquece rapidamente. Em 30 minutos, a temperatura no centro possui um valor da temperatura na superfície da amostra.
Figura 4 - Dependência da temperatura em função do raio, parametrizado no tempo de secagem

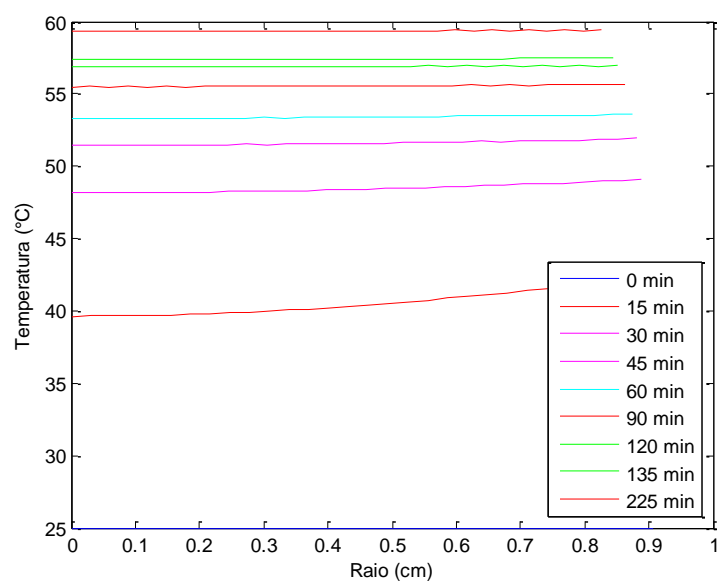

\subsection{Modelo de difusividade variável}

As Figuras 5 e 6 mostram os resultados da simulação para a difusividade mássica em função do conteúdo de água na forma linear e de potência, respectivamente. Pode-se notar uma evolução na precisão do ajuste aos dados experimentais para ambos os modelos, em relação ao modelo de difusividade constante.

Figura 5 - Comparação dos resultados do modelo com difusividade variável linear com os resultados experimentais $\left(a=4,00 \times 10^{-5} ; b=3,70 \times 10^{-4}\right)$

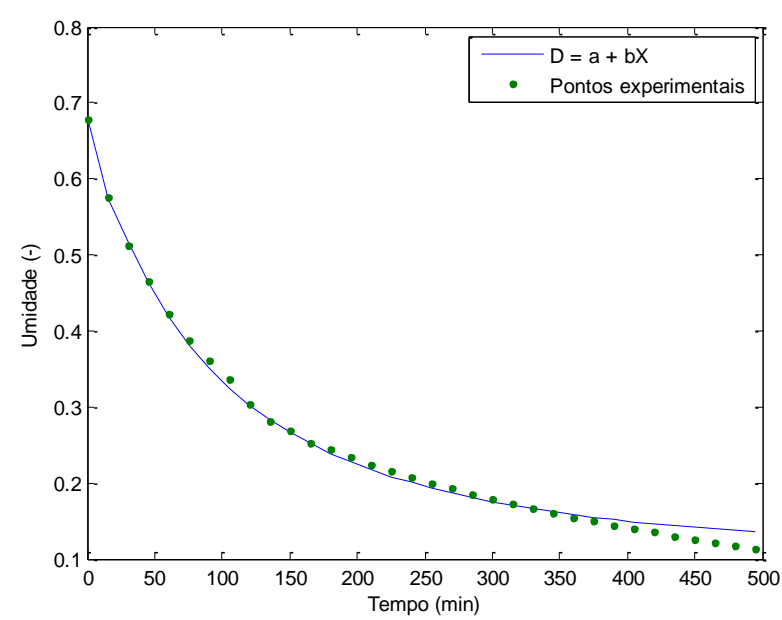

Contudo, é possível observar um pequeno desvio em relação aos últimos pontos experimentais. Para o modelo de difusividade mássica linear a umidade se estabiliza em 0,1357. Para o modelo do na forma de potência, a umidade se estabiliza em 0,1300. 
Figura 6 - Comparação dos resultados do modelo com difusividade variável na forma de potência com os resultados experimentais $\left(a=2,40 \times 10^{-4} ; b=\right.$ $0,405)$

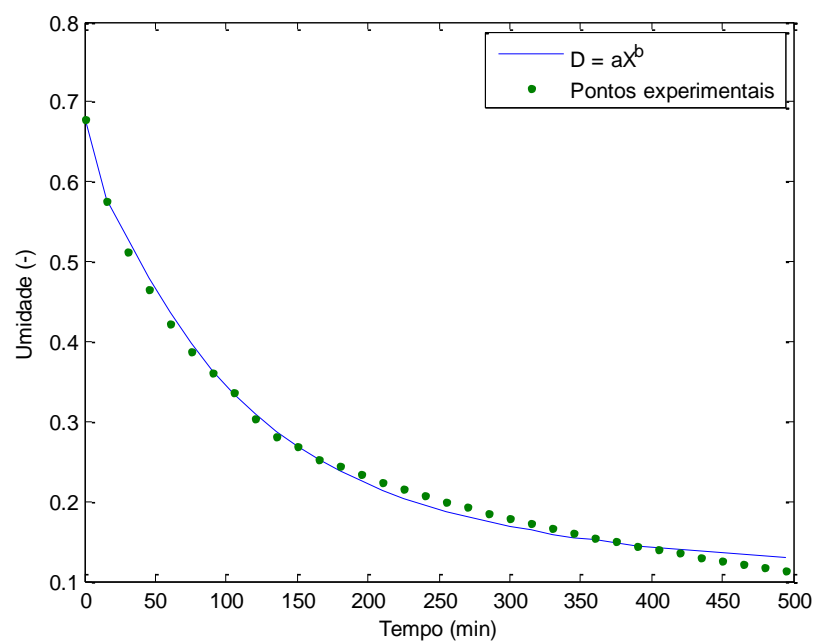

Os modelos apresentados neste trabalho representaram os dados experimentais com boa precisão. Ajustes melhores podem ser feitos se as dimensões angulares forem incluídas. A determinação por meio de experimentos das propriedades específicas da macadâmia também podem contribuir para melhorar os ajustes. Estes modelos podem ser adaptados para a secagem de sementes esféricas em geral e de outros produtos nacionais, como a pimenta rosa.

\section{CONCLUSÃO}

O melhor método para a produção do malte das sementes de macadâmia é o que usa a areia como ambiente de crescimento para o desenvolvimento do processo germinativo. $\mathrm{E}$ em vista do IG, as melhores sementes são as SM, SQD e sem maceração.

Os modelos matemáticos para a secagem das nozes de macadâmia propostos neste trabalho foram capazes de avaliar o perfil de umidade da amostra. $\mathrm{O}$ modelo de difusividade constante apresentou bom ajuste, porém os desvios, principalmente em relação aos primeiros pontos experimentais, sugerem que este não é o melhor modelo para representar o processo de secagem da macadâmia. Como uma segunda abordagem para o problema, os modelos de difusividade variável apresentaram melhores ajustes com desvio em relação aos últimos pontos experimentais

O modelo de transferência de calor avaliou o perfil da temperatura durante o processo de secagem. Como esperado, o modelo mostrou um intenso aquecimento da amostra durante os primeiros $100 \mathrm{~min}$. Apesar de o conteúdo de umidade relativamente baixo da amostra, este modelo inclui o termo de vaporização da água com o intuito de ser o mais generalizado o possível. Este trabalho também contribuiu para o melhor entendimento dos mecanismos de transferência de massa e de calor para uma noz de macadâmia. Em trabalhos futuros, será proposto um modelo de transferência de energia em que a difusividade térmica varie com o tempo e com a posição. Outros modelos de difusividade variável serão analisados e as dimensões angulares serão incluídas para melhorar os ajustes.

\section{NOMENCLATURA}

Bi número de Biot, [-]

Bim número de Biot mássico, [-]

cp calor específico, $[\mathrm{J} /(\mathrm{kg} . \mathrm{K})]$

D difusividade de massa, $\left[\mathrm{m}^{2} / \mathrm{s}\right]$

$\mathrm{k} \quad$ condutividade térmica, $[\mathrm{W} /(\mathrm{m} \cdot \mathrm{K})]$

Le número de Lewis, [-]

$\mathrm{R}$ raio da amostra, [m]

$\mathrm{T}$ temperatura, $[\mathrm{K}]$

$\mathrm{t}$ tempo, [s]

$\mathrm{X}$ umidade, [-]

$\theta \quad$ temperatura adimensional, $\left[\equiv\left(\mathrm{T}-\mathrm{T}_{0}\right) /\left(\mathrm{Tar}-\mathrm{T}_{0}\right)\right]$

$\pi \quad$ calor latente de vaporização adimensional, $\left[\equiv \lambda . \mathrm{X}_{0} / \mathrm{cp}(\mathrm{Tar}-\mathrm{T})\right]$

$\lambda \quad$ calor latente de vaporização, $[\mathrm{kJ} / \mathrm{kg}]$

$\xi \quad$ raio adimensional, $[\equiv \mathrm{r} / \mathrm{R}]$ 


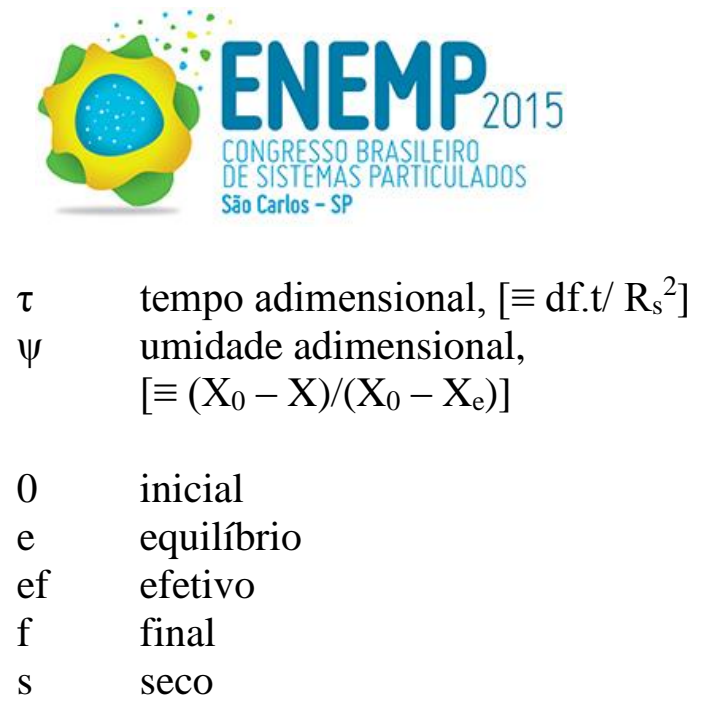

\section{REFERÊNCIAS}

Choi, Y. and Okos, M.R. Effects of Temperature and Composition on the Thermal Properties of Foods. 1986. 93-101p. Journal of Food Process and Applications.

DELGADO, J. M. P. Q. and BARBOSA de Lima.: Grain Drying Simulation: Principles, Modeling and Applications. 2014 48p. Transport Phenomena and Drying of Solids and Particulate Materials, Advanced Structured Materials.

FORTES, M.: A non-equilibrium thermodynamics approach to transport phenomena in capillary-porous media with special reference to drying of grains and foods. 1978. Tese de doutorado,Faculty of Purdue University, United States of America.

MUJUMDAR, ARUN S. - Principles, Classification, and Selection of Dryers. 2009. In: Handbook of Industrial Drying, Third Edition.

PARK, K. J.; ANTONIO, G.C.; OLIVEIRA, R. A.; PARK, K. J. B. - Conceitos de processo e equipamentos de secagem.2007. $121 \mathrm{p}$. Disponível em:<URL:http://www.feagri.unicamp.br> Acesso em: 1 junho 2015

PARK, K. J. B.; PARK, K. J.; CORNEJO, F. E. P.; FABBRO, I. M. D. - Considerações termodinâmicas das isotermas. 2008. 83- 94p. Revista Brasileira de Produtos Agroindustriais. Vol. 10, n. ${ }^{\circ}$ 1. Disponível em $:<$ URL:http://www.deag.ufcg. edu.br/rbpa/rev101/Art1010.pdf $>$. Acesso em: 28 maio 2015.

PENONI, E. S. Caracterização produtiva física e química de cultivares de nogueiramacadâmia. 2011. Tese (Doutorado) Universidade Federal de Lavras, Lavras 2011.

SHERWOOD, T.K. - The Drying of Solids I. 1929a ,12-16p. Industrial and Engineering Chemistry. Vol. 1, n. ${ }^{\circ} 1$.

SHERWOOD, T.K - The Drying of solids - II. 1929b, 976-980p. Industrial and Engineering Chemistry. Vol. 21, n. ${ }^{\circ} 10$.

XINGUO, J., PETER, J. and SHANE, C.:Heat pump assisted continuous drying. Part 2:simulationresults. $1990 . \quad 771-$ 782p.InternationalJournalof Energy Research.

\section{AGRADECIMENTOS}

Os autores agradecem à COOPMAC São Mateus-ES, PRPPG/UFES e CNPq. 